\title{
PTEROSAURS: HOW THEY FLEW
}

by

\author{
James C. Brower
}

The unique nature of reptilian adaptation to flight as exhibited by the pterosaurs of the Mesozoic Era has generated scientific speculation for about 200 years. Paleontologists have visualized pterosaurs as being aerodynamically inferior animals to birds and bats. The following intriguing aerodynamic analysis concentrates on the key points of pterosaur flight - slow flying speeds, maneuverability and low power requirements.

Although Cuvier (180l) first recognized pterosaurs as flying reptiles, not all authors on the subject have endowed them with the power of aerial flight. Wagler (1830) even reconstructed the wings as flippers for swimming. Small pterosaurs have been visualized as active flappers (Fabre, 1976; Wellnhofer, 1975, 1978). Most authors (Heptonstall, 1971; Bramwell and Whitfield, 1974) have interpreted large pterosaurs as gliders and soarers with marginal ability for powered flight. Stein (1975) postulated that large pterosaurs were adapted for slow flapping flight.

From the literature, one gets the general impression that most believed pterosaurs to have been aerodynamically inferior to birds. Cox (1980), for example, stated "one still cannot help feeling that just as a camel is said to be a horse designed by a committee, the pterosaur is the result of that committee turning its attention to birds." This article argues that the flight performance of pterosaurs is best described as being different from, not inferior to, that of birds and bats.

To investigate the aerodynamics of pterosaurs, 16 animals (mostly adults of different species) were restored to "flying configuration" (Brower and Veinus, in press). The mass was determined with a simplified version of a geometrical technique developed by Bramwell and Whitfield (1974) for Pteranodon. Computations are based on a density of $0.9 \mathrm{~g} / \mathrm{cm}^{3}$ (which equals that of a plucked bird). The wingspan is the distance between the wing tips. Measurements of wing area assume that the membrane is not attached to the legs (Padian, 1979; Fig. 1). In addition to simplifying the difficulties of takeoff and landing, this configuration frees the hind legs for locomotion on the ground.

\section{Wing loading}

Readers who are unfamiliar with aerodynamics may wish to consult an introductory treatment on animal flight (Alexander, 1975; Lighthill, 1975, 1977; Pennycuick, 1975; Rayner, 1979).

Wing loading equals the total mass divided by the wing area. Basically, wing loadings dictate flying speeds for gliding and flapping flight. Flying speeds are proportional to the square root of the wing loading. The latter imposes power requirements for flapping flight; higher wing loadings specify larger aerodynamic power outputs from the flight muscles. Excessively high wing loadings produce other problems for flying animals - decreased maneuverability, long runs for takeoff, and high speed landings. Unusually low wing loadings also limit flight performance: pterosaurs with very low wing loadings would have had miniscule flying speeds, too slow to permit controlled flight even in light winds.

Pterosaurs showed low wing loadings relative to most other flying animals of equivalent mass. Consequently, pterosaurs were probably slow and maneuverable flyers with low energy requirements.

\section{Wing design}

There are similarities and differences in the wings of bats and pterosaurs (Fig. 2; Vaughan, 1970a, 1970b; Bramwell and Whitfield, 1974). Both have a membraneous wing in which the main direction of tensioning is roughly spanwise. The common aerodynamic heritage of both groups is a thin-surfaced, cambered wing with a large span at or near the leading edge.

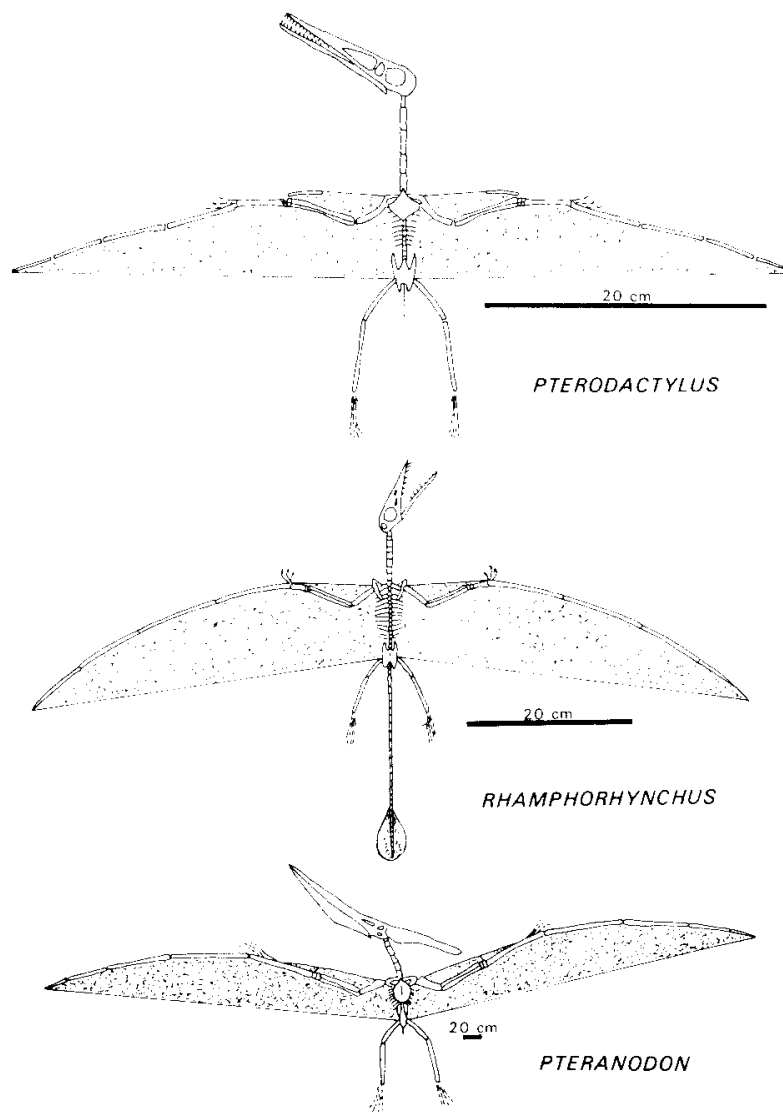

Figure 1. Representative pterosaurs. Pteroductylus antiquus (Soemmering), Upper Jurassic, Solnhof en Limestone, Germany: typical small pterodactyloid, mass $33.8 \mathrm{~g}$. Rhamphorhynchus muensteri (Goldfuss), Upper Jurassic, Solnhof en Limestone, Germany: a rhamphorhynchoid with vane at end of tail, mass 101g. Pteranodon ingens (Marsh), Upper Cretaceous, Niobrara Formation, Kansas, U.S.A.: large member of Pterodactyloidea with long crest, mass $14.9 \mathrm{~kg}$. Wing membranes are stippled; sources of data are listed in Brower and Veinus (in press).

The pterosaur wing membrane was supported by the arm. hand, and digit IV, whereas the bat membrane is borne by the arm, hand, and most digits. The trailing edge of the bat wing extends to the leg, while that of the pterosaur ended along the side of the body. Digits IV and $V$ of the bat function as "wing ribs".

Bats vary the camber and planform of the wing by movements of the arm bones, wing ribs and legs, and by changing tension of the wing membrane. The lack of wing ribs and the fact that the wing membrane was not attached to the legs suggest that pterosaurs were less flexible in these respects. Also, the entire leading edge of a bat wing can function as a flap (Lighthill, 1975), but the equivalent device of a pterosaur was probably confined to the proximal part of the wing.

Comparative morphology suggests somewhat different flight styles. Many bats are well adapted for slow flight with extremely high maneuverability. Although small pterosaurs 

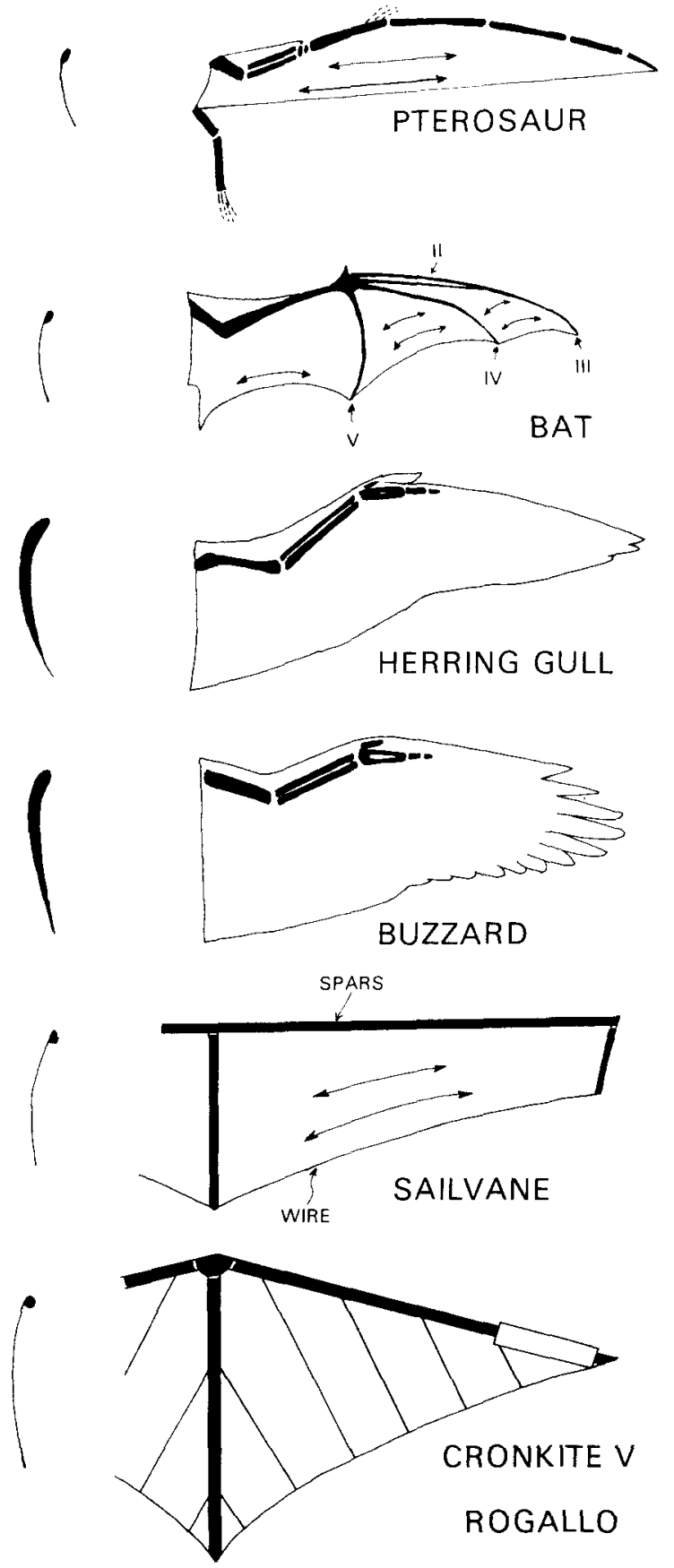

Figure 2. Wing design of various flyers. Wing spars and bones are in black. Arrows indicate direction of tensioning for membranes of some wings. Roman numerals give digit designations for bat. Airfoils are schematic.

had wing loadings that were about the same as in small bats, they probably flew faster and with less maneuverability.

Pterosaurs had thin surfaced wings, whereas the feathered airfoil of a bird is thicker and smoother (Fig.2). The wings of pterosaurs were longer and thinner than most birds' wings, which are more sophisticated aerodynamically than bats and pterosaurs. Birds use the primary feathers and alula to form a slotted wing, and the primary feathers probably operate as individual wings or propellers (Lighthill, 1975, 1977). At least one Russian worker believes that birds can generate suction flow through the wing; since suction flow and slotted wings are high-lift devices in aircraft, they presumably function similarly in birds. These options were not available to pterosaurs nor are they to bats because of their membraneous wing construction. The more intricate aerodynamics of birds, however, do not necessarily produce better flight performance.

EPISODES, Vol. 1980, No. 4
The wings of hang gliders also provide useful paradigms for those of pterosaurs (see Markowski, 1977; Maughmer, 1979; Price, 1975; Strong. 1974). The Princeton Sailwing and Sailvane types possess a leading edge spar which is made of metal tubing. The sail (or wing membrane) is constructed of dacron or some similar material; the trailing edge is formed by a tensioned wire. Thus, the main tensioning of both pterosaur and Sailvane wings extends spanwise.

The largest hang glider is a rogallo-wing termed Cronkite $V$ with a wingspan of $12 \mathrm{~m}$ - roughly the same as that of the Texas pterosaur. The Cronkite wing is less efficient than that of a pterosaur: the trailing edge is free, and so the wing behaves like the sail of a boat. The argument here is not that pterosaurs flew like hang gliders, but that one can apply plots of lift and drag from these aircraft to pterosaurs, and, as pointed out later, discover that the flight performance of pterosaurs was much better than that of a hang glider.

\section{Tentative analogies}

Examination of plots of wing loading versus mass and search for similar wing planforms suggests several general analogies for flight (Fig. 3; Brower and Veinus, in press). Small pterosaurs, with mass below about $150 \mathrm{~g}$, had low wing loadings that intergrade with those of birds such as swifts, swallows, storm petrels, small terns and seagulls as well as fast-flying bats. All these groups are characterized by long, thin wings with high aspect ratios. Although various flying styles are represented, all of these birds and bats are efficient flappers with plenty of power reserves. (Discussion of the flight of birds and bats can be found in Kaufmann, 1970, Lighthill, 1975, 1977, and Vaughan, 1970 a,b).

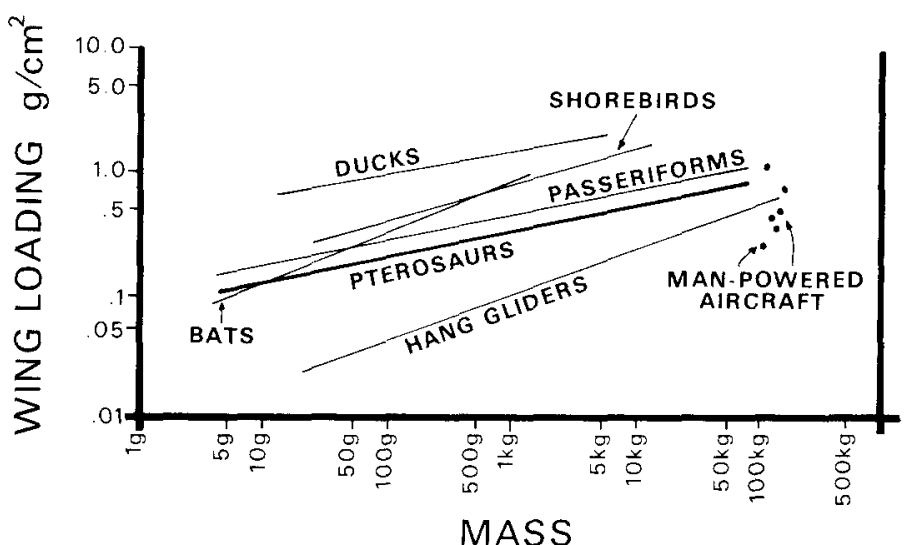

Figure 3. Plot of curves for mass versus wing loading for pterosaurs and various other flyers.

The same was doubtless true of small pterosaurs. A large number of aerodynamic options were open to them. Slightly larger pterosaurs, with mass up to about $300 \mathrm{~g}$, fit with larger terns and some seagulls. These birds are either active flappers or they do both flapping and gliding or soaring.

Within an interval of approximately 0.5 to $10 \mathrm{~kg}$, pterosaurs overlap with or plot close to many soaring birds with low wing loadings, including frigate birds, some seagulls, vultures, condors, and hawks. The wing loadings of the largest pterosaur are within the range of high-performance hang gliders.

These analogies suggest two conclusions: most larger pterosaurs exploited gliding and soaring niches, and the largest pterosaurs were marginally powered animals that were not capable of continuous flapping flight.

\section{Gliding performance}

Given appropriate aerodynamic data, their gliding performance can be easily calculated (Alexander, 1975; Branwell and Whitfield, 1974; Lighthill, 1975, 1977; Pennycuick, 1975 for 
formulae). Computations are based on the dog-faced bat for small pterosaurs and on the Sailvane 2 hang glider airfoil for large forms (data in Pennycuich, 1971; Maughmer, 1979).

Figure 4 illustrates glide polars for various flyers ranging from the large pterosaur Pteranodon to sailplanes. A glide polar is simply a plot of horizontal speed versus vertical or sinking speed. The general position of Pteranodon and other pterosaurs is clear. Both horizontal and sinking speeds are slow; only the man-powered aircraft exhibits a slower sinking speed. The shape of the glide polars for pterosaurs is important: they are peaked, which indicates that individual pterosaurs were restricted to narrow ranges of horizontal flight speeds, at least when gliding.

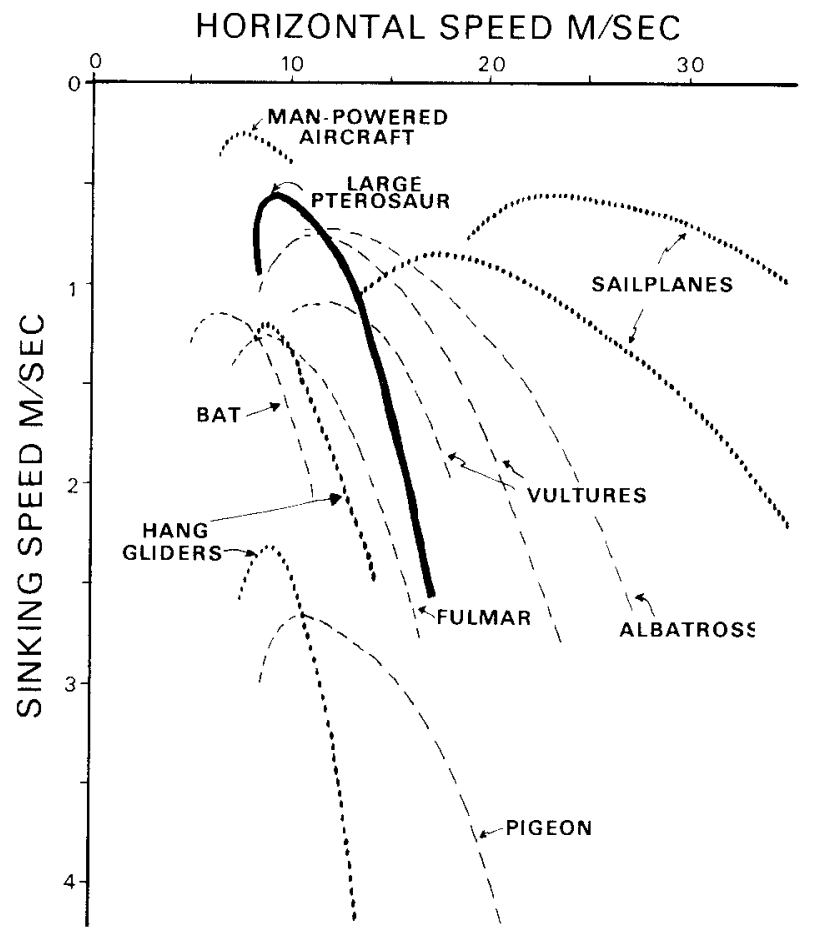

Figure 4. Glide polar for large pterosaur, Pteranodon and various other flyers.

As mentioned before, large pterosaurs were probably mainly soarers and gliders. The horizontal speeds of Pteranodon are approximately equal to those of a good Rogallo-wing hang glider, but the sinking speeds are less for the pterosaur. Although the wing loadings of the two flyers are much the same, the pterosaur developed less drag. This was due to a longer and thinner wing as well as the fact that a pterosaur was much more streamlined than a hang glider, with its frame, pilot, and the numerous wires used for bracing and control. The horizontal speeds of Pteranodon were similar to those of the fulmar but the sinking speeds of the pterosaur were slower.

Compared to vultures and the albatross, pterosaurs exhibited slower horizontal speeds. Their sinking speeds were definitely slower than those of these birds for points at and near the minimum sinking speed at the top of the glide polar. The sinking speeds of the large pterosaur, however, exceeded those of the vultures and the albatross at horizontal speeds of about $12 \mathrm{~m} / \mathrm{sec}$.

Clearly, large pterosaurs were designed for slow speeds, especially when one considers the vertical speed at the point of minimum sink. They probably adapted their flight style to provide the maximum duration in a glide. In addition, low wing loadings provided a high degree of maneuverability and a narrow turning radius. Due to their slow speeds and high maneuverability, large pterosaurs were ideally suited to slope, thermal, and convection current soaring in calm climates. The low wing loadings and slow speeds in flying indicate that large pterosaurs were probably not dynamic soarers such as the albatross and similar birds.

EPISODES, Vol. 1980, No. 4

\section{Powered flight}

This analysis is divided into two aspects - the acrodynamic power required for flight, and the power outputs of the flight muscles. Fast level flight includes horizontal flight speeds which exceed that of the minimum sinking point. Here, the least amount of power necessary is given by the loss of potential energy in a glide, computed by the weight times the sinking speed. The true aerodynamic power requirement for flapping is higher and this equals the power expended to overcome drag (for discussion see Lighthill, 1975, 1977. and Rayner, 1979). Based on a simple kinematic model, this extra power necessary is estimated to be about 24 percent.

Equations developed by Rayner (1979) have been used to determine the amount of power for hovering. The rest of the power curve is sketched between these points to fill in the region for low-speed forward flight. The power that the flight muscles could generate is conjectural: estimates of power available are based on data from birds with low wing loadings. This procedure assumes that pterosaurs had warmblooded metabolisms similar to those of birds or bats. Some morphological evidence, such as the presence of hairs (Sharov, 197!) and pneumatic bones (Bramwell and Whitfield, 1974; Wellnhofer, 1978), supports this view. The power requirements for sustained flight probably demanded a warm-blooded physiology.

Figure 5 contains power curves for three pterosaurs ranging in mass from about $100 \mathrm{~g}$ to $15 \mathrm{~kg}$. The curves for the aerodynamic power required to fly are U-shaped. The low
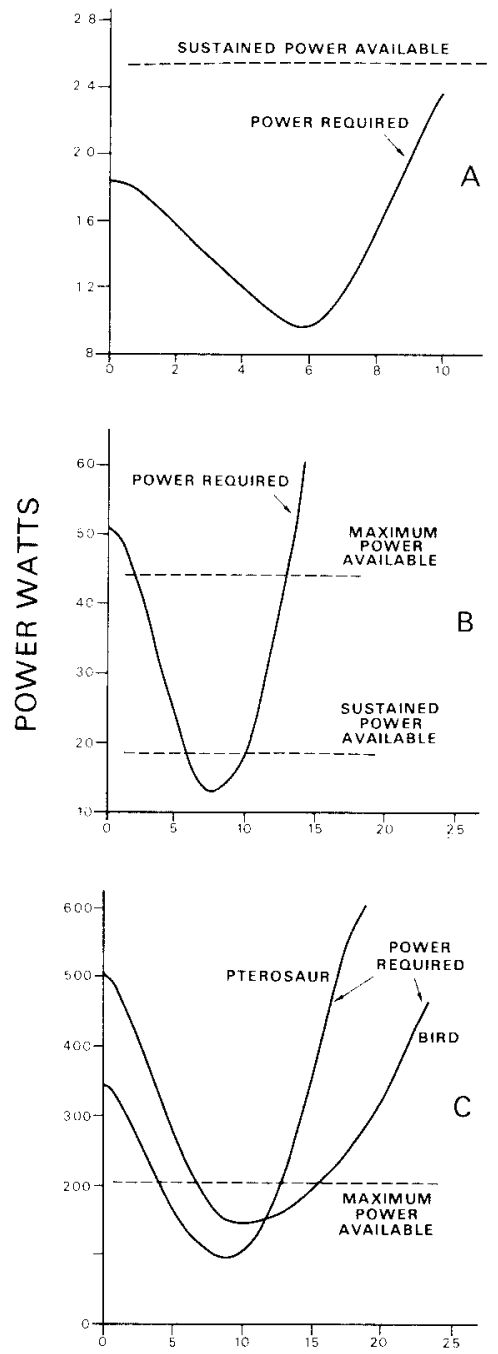

HORIZONTAL SPEED $\mathrm{m} / \mathrm{sec}$

Figure 5. Power curves for three pterosaurs. A. Rhamphorhynchus muensteri (Goldfuss), mass 101g. B. Nyctosaurus gracilis (Marsh), mass $1.86 \mathrm{~kg}$. C. Pteranodon ingens (Marsh), mass $14.9 \mathrm{~kg}$. 
point or trough corresponds to the minimum power speed at which the animal can fly for the least amount of effort. Power requirements increase rapidly toward higher and lower speeds. The Rhamphorhynchus muensteri data are typical for small pterosaurs. The sustained power output was more than sufficient to allow the animal to hover and take off from a standing start. Overall, the performance is comparable to that of a tern or small passeriform bird.

For comparison, the power curve of Pteranodon was plotted against that of a hypothetical soaring bird with the same mass $(15 \mathrm{~kg})$. Note that the power necessary for the pterosaur to fly was lower at almost all of the slower speeds. This is due to the low sinking speeds and the excellent slow speed performance of the pterosaur wing.

According to these computations, Pteranodon did not put out enough power for continuous flapping though the animal could generate sufficient power to fly level or climb for a short time. Such a burst of power must have involved anaerobic muscle metabolism which was maintained only for a short period. Pteranodon could not develop enough power to hover, so take off from a standing start was not possible. The animal, however, could take off and land at an airspeed of several meters per second. The power data show that Pteranodon and other large pterosaurs were soarers and gliders and that the power curve of this pterosaur was probably similar to that of many large and marginally powered soaring birds such as condors.

The power profile of Nyctosaurus (mass $1.9 \mathrm{~kg}$ ) is intermediate between those of large and small pterosaurs. The sustained power output was ample for level flapping flight, though it is unlikely that the Nyctosaurus was a continuous flapper, simply because the metabolic cost of flapping greatly exceeds that for soaring. The paleoenvironment of Nyctosaurus certainly provided opportunities for soaring, which was probably the main flight style for these animals. Given a maximum effort, this pterosaur could take off at an airspeed of around $1.5 \mathrm{~m} / \mathrm{sec}$. The power performance of Nyctosaurus was about the same as in various intermediate-sized soaring birds such as herring gulls and frigate birds.

The maximum power output for Quetzalcoatlus northropi, the giant pterosaur from Texas, with an estimated mass of $75 \mathrm{~kg}$, was barely enough for level flight, and it seems that this animal came close to a theoretical marginally powered flapper. As with birds, the power available for pterosaurs became progressively more marginal relative to that necessary for flight as the mass increased.

\section{References}

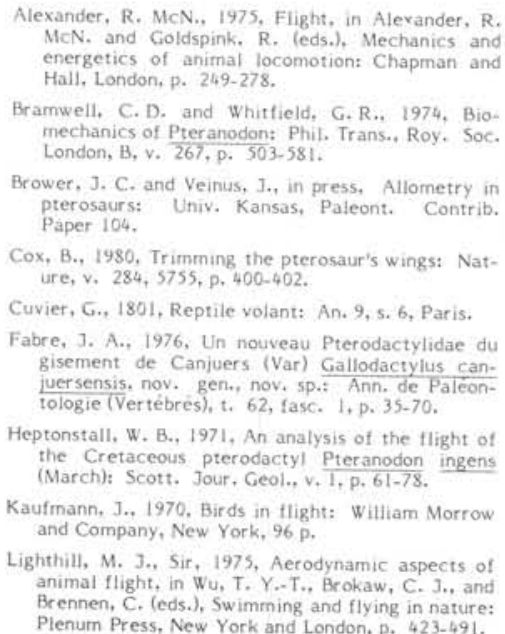
McN. and Goldspink. R. (eds.), Mechanics and (I) techanics of Pteranodon: Phil. Irans.. Roy. Soc.

pterosaurs: Univ. Kansas, Paleont. Contrib.

Cox, B., 1980, Trimming the pterosaur's wings: Nat-

Cuvier, G., 1801, Reptile volant: An. 9, s. 6, Paris. gisement de Can nouveau Pterodactylidae du nov. sp.: Ann. de Paleon

the flight of

and Company, New York, $96 \mathrm{p}$. Plenum Press, New York and London, P, 423-491.

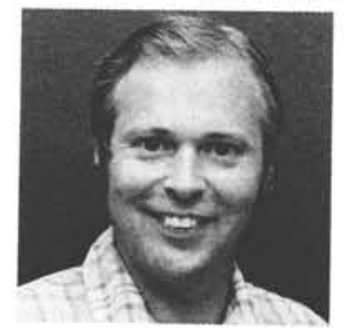

ABOUT THE AUTHOR: James C. Brower is Professor of Geology at Syracuse University, U.S.A. Statistical and numerical applications to paleontology form the focus of his current scientific research. His study of pterosaurs combines a long-standing interest in the relationships between size and shape and low-speed aerodynamics. Prof. Brower is leader of the Biostratigraphy Working Group in IGCP Project 148 - "Evaluation and Development of Quantitative Stratigraphic Correlation Tech-
Rerosaurs have been differentiated into two suborders - the Rhamphorhynchoidea with long tails, and the Pterodactyloidea with short tails (Fig. 1). At least some rhamphorhynchoids had a vane at the end of the tail which functioned as a rudder (Wellnhofer, 1978). The long tail of rhamphorhynchoids probably also provided inertial control (Bramwell and Whitfield, 1974). Most likely, the rhamphorhynchoids were more stable flyers than the inherently unstable pterodactyloids which were "tail-less" flyers. Most authors consider the Rhamphorhynchoidea as the more primitive suborder (Wellnhofer, 1978). If so, pterosaurs followed the path toward flight seen in most flying devices where stable flyers evolve into less stable and more maneuverable configurSummary

Pterosaurs were characterized by slow flight speeds and low power requirements with respect to other flyers of equivalent weights. At low speeds, the long, thin and highly undercambered airfoils provided high lift in conjunction with a low profile and induced drag. Small pterosaurs with masses of up to about $100 \mathrm{~g}$ probably flew by active flapping, as do many birds and bats. Slightly larger pterosaurs were capable of active flapping or intermittent gliding and flapping.

As postulated by most workers (for example, Bramwell and Whitfield, 1974), larger pterosaurs were ideally designed for gliding and soaring in calm climates. Under such conditions, low flying speeds and light wing loadings ensured reasonable flight performance in the face of winds. Compared to soaring birds, the gliding performance of pterosaurs at the minimum sinking point was superior because the vertical or sinking speeds were lower. The main aerodynamic adaption to gliding seen in pterosaurs was probably an attempt to maximize duration. The power requirements of pterosaurs were lower than in most birds of the same mass.

The penalty of the basic pterosaur plan was probably specialization, in that the animals were restricted to a narrow range of flight speeds. Although their power requirements were higher, soaring birds used wider ranges of horizontal speeds than large pterosaurs. The higher wing loadings and flying speeds of soaring birds afford the variability of gliding performance required for more turbulent conditions. In general, the bird adaptation to flight is much broader than that of pterosaurs. It is tempting to speculate, therefore, that specialization for a narrow range of relatively slow flight speeds may have contributed to the extinction of pterosaurs.

Lighthill, M. J., Sir, 1977, Introduction to the scaling of aerial locomotion, in Pedley, T. J. (ed.). Scals effects in animal locomotion: Academic Press, p. 365.404.

dynamic characteristics of eight saitwing sections: NASA Conference Pub. 2065, 1, 8 p.

Padian, K., 1979, The wings of pterosaurs: a new ook: Discovery, v. 14, 1, p. 20-29.

Pennycuick, C.J., 1971, Gliding flight of the dog. faced bat Rouseltas aegyptiacus observed in

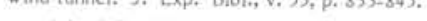
Penycuick, C.J., 1975, Mechanics of flight, in Farner, D.S. and King, J.R. (eds.), Avian Biology: ic Press, v, 5, 75 p.

Skime, C. B., 1975, Hang glider directory: Ground Skimmer Mag., Issue 35, $68 \rho$.

flight. Part 2. The A vortex theory of animal Fluid Mechanics, v. 91, 4, p. 731-763.

Sharov, A.G., 1971, New flying reptiles from the Russian): Pateon or Kazaknstan and Kirgizia tin 130. P. 104.113. Anst. Akad. Nauk. SSSR, Trudy,

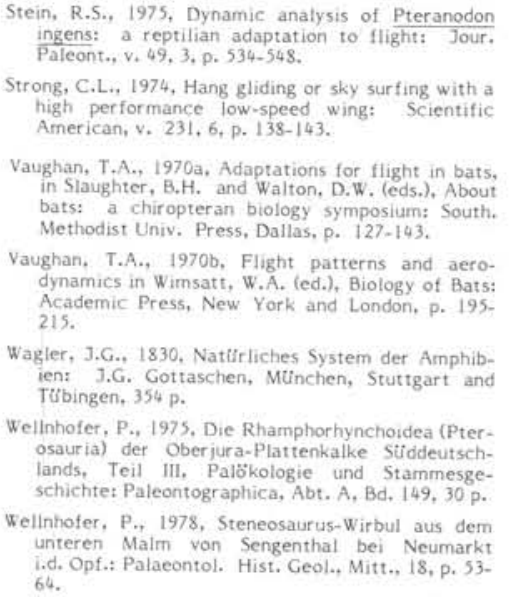

ingens: a reptilian adaptation to flight: Jour.
Books, M.A., 1977. The hang glider's bible: Tab 